\title{
DINÁMICAS DE LA PROPIEDAD PRIVADA EN CHIAPAS: LOS CONDUEÑAZGOS DE COMITÁN, 1885-1935
}

\author{
Armando Méndez Zárate ${ }^{1}$ \\ Universidad Nacional Autónoma de México
}

\section{INTRODUCCIÓN}

G ste trabajo explora el desarrollo de una forma de propiedad $\mathcal{L}_{\text {privada utilizando el caso de los condueñazgos existentes a }}$ finales del siglo xix y principios del xx. Los condueñazgos ubicados en Comitán y en poblaciones aledañas como Socoltenango y San Bartolomé de los Llanos ${ }^{2}$ ya existían como propiedades privadas, al menos desde el siglo xviıI. ${ }^{3}$ Pero me interesa destacar los condueñazgos que se formaron y modificaron después de la entrada en vigor del Código Civil mexicano de 1884 y la Ley de Rentas Municipales del estado de Chiapas de 1895,4 que estuvo encaminada a formar padrones catastrales, fomentar la titulación

Fecha de recepción: 15 de abril de 2020

Fecha de aceptación: 24 de septiembre de 2020

1 Programa de Becas Posdoctorales en la Universidad Nacional Autónoma de México, becario del Centro de Investigaciones Multidisciplinarias sobre Chiapas y la Frontera Sur. Asesorado por la doctora Dolores Camacho Velázquez. 2 En 1939 cambió de nombre a Venustiano Carranza.

3 Barrera, Las terrazas; Ruz, Savia India, pp. 137-156.

4 SÁnchez, "Reformas y finanzas", p. 153; Congreso, Ley y reglamento. 
individual de la tierra y desaparecer la propiedad comunal, como los ejidos de comunidades y ayuntamientos. ${ }^{5}$

El objetivo es estudiar los condueñazgos comitecos como una forma de propiedad comunal privada. Al respecto, realizaré una explicación puntual sobre esta consideración, pues se debe diferenciar el tipo de dominio y propiedad de los condueñazgos. En Chiapas se han explorado las propiedades comunales indígenas y de los ayuntamientos en los pueblos. ${ }^{6}$ En especial, la coyuntura de la desamortización de tierras comunales ocurrida entre 1826 y 1856. Sobre este aspecto, Dolores Palomo Infante ha propuesto que los pueblos y particulares emplearon las diferentes formas de territorialidad y jurisdicciones contenidas en la legislación agraria estatal y federal para tratar de conservar sus propiedades comunales.? Los condueñazgos y las propiedades mancomunadas fueron una manera de perpetuar los derechos de propiedad sin que implicara un fraccionamiento de los terrenos, manteniendo la propiedad comunal. No obstante, me concentraré en las propiedades privadas de dos o más dueños, las cuales también se vieron impactadas por las leyes desamortizadoras locales de 1826 y nacionales de 1856.

Antes de comenzar con el análisis, quisiera definir el término de condueñazgo que emplearé en este trabajo y que lo tomo de Pérez Castañeda, quien lo identificó como una "modalidad de tenencia del régimen de propiedad privada durante el siglo xIx, cuyo común denominador era que los bienes [la tierra] pertenecían a más de una persona”. ${ }^{8}$ Aunque el condueñazgo

5 SÁnchez, "Reformas y finanzas"; SÁnchez y Ortiz, "Fincas rústicas", p. 150.

${ }^{6}$ De Vos, Vivir en frontera; García de León, Resistencia; OrTIz, "Lengua e historia”; Ortiz, "Abogados y apoderados"; Pedrero Nieto, "La evolución del ejido"; Reyes Ramos, El reparto de tierras; Palomo, "Las tierras en disputa"; Torres Freyermuth, "La legislación agraria".

7 Palomo, "Las tierras en disputa", p. 515.

8 Pérez, "Los condueñazgos", p. 188. 
no se debe confundir como una categoría más de las estructuras agrarias, pues no "encarnó en ningún momento un modelo específico de propiedad agraria en sí mismo”. ${ }^{9}$

Así, el eje principal de análisis resalta las dinámicas de los derechos de propiedad de los condueñazgos comitecos. Por su parte, el sustento teórico se basa en la propuesta de estudiar la historia de la propiedad rural que considera las relaciones y actividades sociales manifestadas en las formas cotidianas de "acceder a los recursos y formas de disfrutar de los llamados derechos de propiedad, y también por los derechos y prácticas de uso, es decir, por las diferentes formas de ser propietario". ${ }^{10}$

El interés de estudiar los condueñazgos en Chiapas surgió por el análisis documental de las notificaciones del "derecho de tanto" entre condueños y los libros notariales que dan cuenta de los terrenos considerados como condueñazgos, localizados en el Archivo Histórico de Comitán. ${ }^{11}$ Estas herramientas me permitieron extraer información puntual sobre las dinámicas de los condueñazgos, como la superficie, el número de condueños y su parentesco, los compradores y vendedores de derechos, los costos de las transacciones y los usos agrícolas de los terrenos. Además, las notificaciones del "derecho de tanto" entre los condueños me posibilitó ver las tensiones en el aprovechamiento de los recursos naturales (aguas, maderas, pastizales) y los acuerdos legales y extrajudiciales sobre su aprovechamiento.

De esta forma, primero revisé la geografía y sociedad de Comitán, con el fin de resaltar las características del territorio fronterizo con Guatemala. En la segunda parte del trabajo analizo los condueñazgos, contextualizando las condiciones económicas y políticas que permitieron su desarrollo en Comitán. Posteriormente, me centraré en las características de los condueñazgos

\footnotetext{
9 Pérez, “Los condueñazgos”, p. 188.

10 Congost, Tierras, leyes, historia, pp. 14-15.

11 Resguardado por el cuid-Unicach en Tuxtla Gutiérrez, Chiapas.
} 
que se formaron en el entonces departamento chiapaneco de Comitán, especialmente los de la segunda mitad del siglo xix y aquellos que superaron el periodo revolucionario (1910-1920).

\section{UBICANDO EL TERRITORIO COMITECO}

Comitán se ubica en un punto estratégico de la geografía de Chiapas, entre la confluencia de la Depresión Central, Los Altos y la Selva Lacandona (véase el mapa 1). ${ }^{12}$ Estas características físicas permiten a las llanuras de Comitán contar con bastos recursos hídricos y forestales, muy aptos para las actividades agrícolas y ganaderas. Desde la época colonial, en esta zona se asentaron propiedades privadas y eclesiásticas muy vastas, dedicadas a la cría y comercialización de ganados, además de a la siembra de productos agrícolas como trigo y maíz. ${ }^{13}$

Las llanuras de Comitán y la cercanía de poblaciones importantes facilitaron el paso de los caminos provenientes de Guatemala. Comitán fue el centro urbano principal y lugar de paso en el camino entre los centros administrativos y políticos de la región, como San Cristóbal de Las Casas y el occidente guatemalteco. Esta posición permitió a los comerciantes comitecos tener un contacto comercial, social y político con Guatemala y el resto de Chiapas. También existían otros poblados relevantes para el comercio, la agricultura y la ganadería, como Zapaluta (La Trinitaria), Las Margaritas, Los Riegos y Tzimol. Además de San Bartolomé de los Llanos, Pinola (Las Rosas) y Teopisca (véase el mapa 1), los cuales se conectaban con los llanos comitecos a través de los caminos y el comercio.

Las condiciones económicas y demográficas de Comitán se acentuaron por su condición fronteriza con Guatemala. Estas características provocaron la emergencia de un centro político

12 Viqueira, “Chiapas y sus regiones”, p. 34.

13 Ruz, Savia india. 


\section{Mapa 1 \\ UBICACIÓN DE COMITÁN, CHIAPAS}
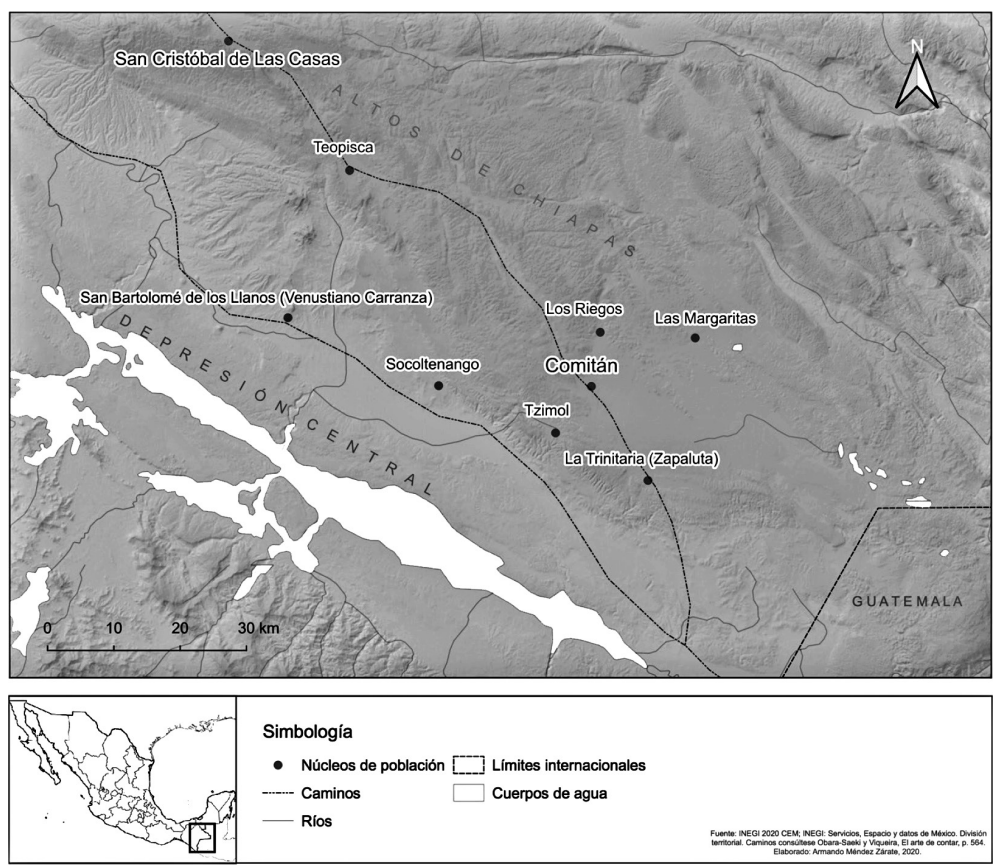

administrativo apoyado por la riqueza agrícola, ganadera y comercial. Después del proceso de independencia en Chiapas en 1821, ${ }^{14}$ Comitán se consolidó como la sede de un departamento territorialmente extenso, que compartía una frontera indefinida con Guatemala y territorios aún sin ocupación permanente en la Selva Lacandona y otros terrenos fértiles de la Depresión Central.

La población de Comitán y pueblos aledaños fue una de las más numerosas de Chiapas durante el siglo XIX y principios del xx. ${ }^{15}$

14 Pedrero, “Las divisiones políticas”, pp. 231-242.

15 Pedrero, "Las divisiones políticas", pp. 252-254. 
Los habitantes estaban concentrados en Comitán y en las rancherías y fincas. ${ }^{16}$ La población indígena tojolabal fue desplazada desde el siglo xviI conforme avanzaba la frontera agrícola, mediante la apropiación de tierras consideradas baldías y la formación de fincas. ${ }^{17}$ De esta forma, se conformaron poblaciones en Comitán con presencia indígena y ladina. Esta característica ocasionó tensiones entre los grupos sociales en los pueblos, a pesar de los informes parroquiales de mediados del siglo xix que señalaba a los indígenas de Comitán como "los más tranquilos del estado" ${ }^{18}$ Las características demográficas de Comitán y los atributos físicos favorecieron las actividades comerciales, agrícolas y ganaderas, tanto legales como ilegales. Estas condiciones influyeron en el desarrollo de las propiedades privadas, especialmente sobre los condueñazgos, los cuales se analizarán en detalle.

\section{LA DESAMORTIZACIÓN EN CHIAPAS DEL SIGLO XIX: ¿ORÍGENES DE LA PROPIEDAD PRIVADA?}

En Chiapas el proceso de desamortización de tierras consideradas baldías o nacionales, incluidos los propios de los pueblos $\mathrm{y}$ comunidades indígenas bajo el resguardo de los ayuntamientos, comenzó a partir del 1o de septiembre de 1826, cuando el Congreso estatal chiapaneco, "queriendo sacar a la agricultura del abandono", ${ }^{19}$ aprobó un decreto que buscaba convertir en propiedades privadas las tierras que no eran ejidos de los pueblos.

El decreto de 1826 dispuso esquemáticamente la manera de conducir las denuncias, medición y titulación de las tierras "baldías o nacionales", además de los propios. Igualmente, de

\footnotetext{
16 BARrera, Las Terrazas.

17 Ruz, Savia india.

18 AHDSCLC, carp. 3437, exp. 23, f. 1.

19 Congreso, Colección de las leyes, p. 3.
} 
los mecanismos legales y atribuciones de las autoridades locales (ayuntamientos) e intermedias (juzgados de primera instancia, prefectos, subprefectos) para intervenir en dichos trámites. Al respecto, en los artículos 3 y 4 del decreto de 1826, se otorgaban facilidades para que los terrenos fueran titulados por aquellos que estuvieran en posesión de la tierra, especialmente si pretendían "reducirla" como una propiedad privada.

El Congreso del estado de Chiapas volvió a legislar sobre el decreto del 1o de septiembre de 1826, modificando algunos artículos relacionados con los ejidos de los pueblos y reglamentando los trámites de denuncias. El decreto reformado de 1827 se enfocaba en proteger los ejidos de los pueblos, por lo que antes de poner a la venta los baldíos y parajes que los ayuntamientos habían seleccionado, era necesario conocer su superficie y límites. No obstante, el artículo 7 fue el más destacado, pues prohibía la adquisición de tierras de ejidos para titularlas como una "propiedad legítima y legalmente adquirida". ${ }^{20}$

En Chiapas los decretos estatales de 1826 y 1827 son considerados el fundamento legal de las primeras apropiaciones de tierras comunales pertenecientes a los pueblos. ${ }^{21}$ Igualmente, los decretos permitieron la formación de condueñazgos en Los Altos y Comitán. Este argumento lo expondré a continuación; sin embargo, me interesa resaltar que éste no fue un proceso instantáneo ni rápido, pues dependió de un conjunto de circunstancias legales, políticas y económicas; de ahí la necesidad de distinguir los casos y regiones en Chiapas, donde cobraron importancia estas formas de propiedad privada. Incluso, el análisis tiene que extenderse más allá de las leyes desamortizadoras de 1856, pues se conoce poco sobre las consecuencias de estas leyes para las comunidades indígenas y las estructuras agrarias en Chiapas. ${ }^{22}$

20 Congreso, Colección de las leyes, p. 5.

${ }^{21}$ De Vos, Vivir en frontera, p. 161.

22 Palomo, "Las tierras en disputa”, p. 487. 
Sin embargo, propongo que una de las repercusiones de estos decretos consistió en la formación y continuidad de los condueñazgos como una forma de propiedad privada, al menos para el caso de Comitán y Los Altos. Por ejemplo, en San Cristóbal de Las Casas, el terreno de Agua de León o Tierra Caliente fue adquirido de manera mancomunada, bajo el amparo de los decretos de 1826 y 1827 por María del Carmen Gómez y José Elías Ruiz. La condición mancomunada del terreno no se perdió con el tiempo, esto a pesar de las herencias y compras por las que pasaría la propiedad. ${ }^{23}$ Igualmente, en las cercanías de Comitán, Manuel Aguilar compró tierras del predio llamado Santo Domingo, que lo "había reducido a propiedad privada por compra al gobierno". ${ }^{24}$ Posteriormente, en 1886 Máximo Aguilar disputó legalmente el terreno de su padre, que había pasado a ser un condueñazgo. Incluso, los condueños agregaron otros terrenos a la propiedad y le cambiaron el nombre a Lopoj.

Mediante ambos casos, es posible rastrear algunos orígenes de los condueñazgos como consecuencia de los decretos de 1826 y 1827, además de entender cómo ocurrió el proceso de desamortización de tierras y la formación de propiedades privadas. Algunas de esas propiedades se conformarían en terrenos mancomunados privados siguiendo caminos diferentes, como: la compra de derechos de propiedad, la constitución de condueñazgos mediante actas notariales, tierras desamortizadas de corporaciones religiosas ${ }^{25} \mathrm{o}$ por herencia familiar.

Las transformaciones jurídicas de la primera mitad del siglo xIx en Chiapas estuvieron motivadas por los cambios administrativos del gobierno del estado, alternándose sucesivamente proyectos políticos con visiones económicas y sociales muy distintas. En Chiapas el primer liberalismo político (1824-1835)

\footnotetext{
23 AHJLA, No. 5497, c. 40, exp. 5494, f. 1.

24 AHC-CUID, No. 646, exp. 2319, f. 1.

25 AHDSCLC, carp. 2691, exp. 133; AHDSCLC, carp. 2704, exp. 4; AHDSCLC, carp. 3451, exp. 38; AHDSCLC, carp. 5720, exp. 19.
} 
dio paso a un sistema centralista de gobierno que también impulsó sus propias disposiciones agrarias. ${ }^{26}$ No obstante, para las propiedades privadas, como los condueñazgos, los cambios en las leyes agrarias más relevantes vendrían con la restauración de la república (1867) y la administración porfirista (1876-1910).

Recientemente han surgido otros enfoques que han revisado el impacto de las leyes desamortizadoras decimonónicas para las propiedades privadas y comunales en Chiapas. ${ }^{27}$ En contraparte, los estudios sobre los condueñazgos han sido abordados de manera circunstancial. Por ejemplo, Rocío Ortiz Herrera logró localizar propiedades mancomunadas en la vertiente del Mezcalapa a finales del siglo XIX, ${ }^{28}$ al igual que propiedades de campesinos unidos en la región de la selva en Tila durante el siglo xx..$^{29}$ Igualmente, existen evidencias de condueñazgos en el Soconusco a finales del siglo XIX. ${ }^{30}$ Finalmente, resaltaré el trabajo de Miguel Ángel Sánchez Rafael, quien hizo una aproximación a las fincas rústicas mancomunadas y su relación con el fisco estatal durante la segunda mitad del siglo XIX. ${ }^{31}$

Para Comitán, existe el texto clásico de la historiografía chiapaneca de Mario Humberto Ruz sobre las fincas comitecas en los siglos XVIII y XIX, ${ }^{32}$ quien documenta la formación y transformación de algunos condueñazgos y terrenos mancomunados. También, Gloria Pedrero Nieto ubicó condueñazgos como una forma de propiedad privada en los valles de Teopisca, cercanos a

\footnotetext{
${ }^{26}$ Méndez, “Estructuras agrarias”, p. 258.

27 Barrera, Las Terrazas; Palomo, "Las tierras en disputa"; Pedrero, "La evolución del ejido", Pedrero, "La nueva estructura"; SÁnchez y Ortiz "Fincas rústicas".

28 OrTIZ, "Lengua e historia".

29 Reyes, El reparto de tierras, p. 318.

30 Armando Méndez Zárate, "Denunciantes y denuncias de terrenos en el Soconusco, México, 1863-1878”, texto inédito.

31 SÁnchez, "Reformas y finanzas", pp. 159-161.

32 Ruz, Savia india.
} 
Comitán, ${ }^{33}$ y Óscar Barrera consiguió identificar condueñazgos y propiedades privadas mancomunadas en el área de Comitán. ${ }^{34}$

Los estudios anteriores permiten ubicar los condueñazgos en regiones diferentes de Chiapas. Este tipo de aproximaciones puede aportar una perspectiva de las consecuencias de las leyes desamortizadoras en las comunidades indígenas y ladinas de Chiapas, ${ }^{35}$ en línea con los debates actuales que apuntan que el proceso desamortizador en México no fue homogéneo ni generalizado. ${ }^{36}$ Además, la propuesta de este trabajo llama a distinguir a los condueñazgos, no como una estrategia de los pueblos para conservar sus bienes comunales. ${ }^{37}$ En su lugar, los condueñazgos comitecos revelan la conservación de propiedades particulares que permanecieron proindivisas.

\section{LOS CONDUEÑAZGOS COMITECOS}

La conformación de los condueñazgos comitecos como una forma de propiedad privada tiene sus antecedentes en el siglo XVII, ${ }^{38}$ aunque en el contexto del siglo XIX el condueñazgo como un modelo de propiedad específica ${ }^{39}$ no estuvo plenamente regulado, a diferencia del término de comunero, definido como "el que tiene alguna cosa mueble o raíz [...] en común con otro”. ${ }^{40}$ De esta forma, el dominio de los propietarios sobre el terreno era imperfecto, pues estaba fraccionado entre diferentes personas. ${ }^{41}$

\footnotetext{
33 Pedrero, "La nueva estructura”, pp. 315-316.

34 Barrera, “Las Terrazas”, pp. 39, 519.

35 Palomo, “Las tierras en disputa”, p. 487.

36 Kourí, "Sobre la propiedad comunal”.

37 Escobar OHMStede, "Los condueñazgos indígenas”; Escobar OHMSTEde y Gordillo, “¿Defensa o despojo?”; Fandos, "La formación histórica”; Pedrero Nieto, "La nueva estructura agraria”.

38 Ruz, Savia india.

39 Pérez, “Los condueñazgos”, p. 188.

40 EsCriche, Diccionario razonado, p. 558.

41 EsCriche, Diccionario razonado, p. 649.
} 
Al respecto, la documentación judicial y notarial sobre los condueñazgos comitecos también emplea los términos de mancomunados o en común para referirse a los terrenos compartidos por los condueños o copropietarios.

En el caso de los condueñazgos comitecos, ¿cómo es posible que una propiedad sea comunal y también privada? La diferencia radica en el tipo de dominio que las personas tienen en el condueñazgo. Es una propiedad mancomunada o en común porque la comparten con otras personas, sin perder el dominio directo sobre el terreno, y es privada porque los condueños no pertenecen a una comunidad indígena o ladina, y por lo tanto el terreno no forma parte de un bien común de algún pueblo o ayuntamiento.

Las dinámicas en los derechos de propiedad de los condueños sobre los terrenos se pueden apreciar en las regulaciones dispuestas en el Código Civil Federal de 1884 y en la Ley de Rentas Municipales del estado de Chiapas de 1895, ${ }^{42}$ las cuales presionaron a los condueños para dividir los terrenos que no tuvieran una delimitación interna, o bien para vender su parte correspondiente a fin de que se pudiera titular por el comprador, pasando de un dominio imperfecto a un dominio directo.

Los mecanismos legales para la división de los condueñazgos tuvieron varios caminos, destacando el deslinde de la propiedad entre condueños para después titularla y venderla, además de la división por hijuela, ocurrida cuando el condueñazgo lo heredaban los hijos y decidían vender o titular su parte de forma individual. La división por hijuela en Comitán se distingue por estar protocolizada ante notario público y es otra forma legal de repartir bienes poseídos en mancomún. También permite observar otra variante regional, pero desde la propiedad privada,

\footnotetext{
${ }^{42}$ Ley de Rentas Municipales de 1895 en Sánchez, "Reformas y finanzas”, p. 153.
} 
distinta de los repartos de tierras comunales realizadas en Michoacán mediante hijuelas. ${ }^{43}$

El análisis de los condueñazgos comitecos partió de las notificaciones de intención de venta ingresadas por un condueño en el Juzgado de Primera Instancia en Comitán preguntando a los otros condueños si querían ejercer su "derecho de tanto" previsto en el artículo 2843 del Código Civil de 1884. Pues si no se notificaba a los condueños mediante aviso notarial o judicial, "la venta no produciría efecto legal alguno", ${ }^{44}$ en especial cuando el comprador era una "persona extraña" 45 para los condueños, lo que implicaba una ausencia de parentesco familiar o relación de negocios entre los condueños.

El artículo 2843 del Código Civil posibilitaba que los condueños adquirieran el dominio de derecho de otro condueño utilizando el "derecho de tanto". ${ }^{46}$ Esto a pesar de que existiera un arreglo previo entre el vendedor y el posible comprador. Sin embargo, en Comitán registré pocos casos de condueños interesados en ejercer el "derecho de tanto". ${ }^{47}$ Las respuestas de los condueños a los avisos del "derecho de tanto" revelan las tensiones entre los propietarios por el aprovechamiento de los recursos naturales, especialmente los derechos de propiedad sobre las aguas, maderas y pastizales existentes en la propiedad. Además, ofrecen una perspectiva sobre la administración de los condueñazgos, pues revelan la existencia de acuerdos legales y extrajudiciales entre los condueños que regulaban el uso de los recursos naturales.

A partir de esos factores, presentaré los rasgos característicos de los condueñazgos de Comitán, particularmente de los registrados entre 1885 y 1935. En total fueron 33 propiedades

\footnotetext{
43 Venegas, "El proceso de reparto".

${ }^{44}$ Código Civil, p. 549.

45 AHC-CUID, No. 1786, exp. 121, f. 1; AHC-CUID, No. 2745, exp. s/n, f. 1.

${ }^{46}$ Código Civil, p. 549.

47 AHC-CUID, No. 1669, exp. 16, f. 1; AHC-CUID, No. 1712, exp. 98, f. 1.
} 
privadas que estuvieron constituidas en condueñazgos. Aunque debieron haber existido más condueñazgos, solamente consideré las notificaciones consignadas en los juzgados de Primera Instancia de Comitán y San Cristóbal de Las Casas y otras registradas ante notario público en Comitán. Igualmente, logré identificar al menos dos sociedades agrarias constituidas entre 1901 y 1914, pero abordaré más adelante este tema.

Los condueñazgos estuvieron conformados por propiedades privadas proindivisas, lo que implicaba la ausencia de una división clara entre los condueños respecto a su parte en la propiedad. ${ }^{48}$ Los condueños en algunos casos tenían bastante clara la extensión que poseían dentro de un terreno en condueñazgo. La superficie de terreno de cada condueño variaba considerablemente, desde 5 hasta 2000 hectáreas. Estas cifras son relativamente pequeñas comparadas con las extensiones de los condueñazgos en San Luis Potosí, las cuales sobrepasaban las 8000 hectáreas de superficie. ${ }^{49}$

Por el momento no dispongo de datos suficientes para determinar la extensión total en hectáreas de cada condueñazgo debido a que los condueños no reportaban la superficie total, por omisión, o bien tratando de ocultar el área del condueñazgo. Sobre este asunto intervinieron múltiples factores de "orden económico, productivo, presupuestario, operativo y geográfico".${ }^{50} \mathrm{La}$ agrimensura de las propiedades requería de una inversión de los condueños, los cuales no todos podían o querían asumir, pues implicaría la contratación de un agrimensor, la formación de planos y la creación de listas de condueños con consecuencias fiscales, ${ }^{51}$ pues los condueños quedarían plenamente identificados para fines catastrales y legales.

\footnotetext{
48 Rangel Silva, “Los comuneros”, pp. 944-945.

49 Aguilar Robledo, “Los condueñazgos”.

50 FAndos, "La formación histórica”, p. 70.

51 FAndos, "La formación histórica”, p. 70.
} 
Los condueñazgos se localizaban mayormente en Comitán, Socoltenango, Las Margaritas, Chicomuselo, Tzimol, Los Riegos, Ajayaxh, Zapaluta y Yocnajab, aunque destacaban los que se constituyeron en pueblos más pequeños, como Los Riegos, Ajayaxh, Yocnajab, Tzimol y Las Margaritas (véase el mapa 1). Por su parte, la residencia de los condueños se ubicaba en Tzimol, Comitán, Zapaluta y Las Margaritas, pues en las solicitudes de notificación se declararon vecinos de esos pueblos.

La forma de organización de los condueñazgos en el ámbito social fue bastante clara en los casos analizados, con condueños emparentados por redes familiares, o bien, unidos por intereses comerciales. Destacan los condueñazgos donde los miembros eran familiares directos y aquellos conformados por hermanos por herencia familiar. De esta forma, el número de condueños declarados por propiedad oscilaba entre 2 y 24 .

Los condueños formaban parte de familias comitecas que tenían negocios comerciales y agroganaderos, como los Argüello, Gordillo, Pinto, Cristiani, Aguilar y Cancino. También hubo otros actores sociales que se incorporaron como condueños a las propiedades de las familias anteriores. Al respecto, es interesante observar cómo en las notificaciones los condueños se refieren a su propiedad como "terreno mancomunado" o "proindiviso". ${ }^{52}$ Por su parte, a los miembros que compartían el terreno se les identificaba como condueños o copropietarios.

En este sentido, el carácter proindiviso de la propiedad expresado por los condueños como copropiedad o mancomunidad acaba por definir el término de condueñazgo para referirse a esa forma de ejercer el domino imperfecto de la propiedad. ${ }^{53} \mathrm{La}$ condición de proindiviso de un terreno corresponde a una propiedad sin límites internos, a pesar de tener más de dos dueños.

52 AHC-CUID, No. 2010, exp. s/n, f. 1; AHC-CUID, No. 1785, exp. 115, f. 1. ${ }^{53}$ Los artículos 733, 734 y 735 del Código Civil de 1884 recogen los derechos de los copropietarios. 
La ausencia de una división física y medidas de la propiedad provocó que los condueños tuvieran una idea vaga de los límites de los terrenos y de la parte que les correspondía. Estas características no son únicas de Comitán, pues en San Luis Potosí también ocurría lo mismo entre los condueños. ${ }^{54}$ En la documentación, si un condueño alegaba desconocer los límites de sus propiedades, ya fuera deliberadamente o porque realmente así ocurría, enfatizaba el estado proindiviso del terreno.

No obstante, quisiera regresar a los términos utilizados por los condueños cuando se refieren a sus propiedades. En primer lugar, la palabra mancomunidad era empleada cuando el condueñazgo tenía orígenes en una propiedad heredada, esto es, cuando los padres transmitían por herencia a todos los hijos la propiedad, pero sin dividirla. El Código Civil de 1884 permitía este tipo de acciones, incluso obligaba a los herederos a notificar a todos los copropietarios de las acciones que pretendieran hacer sobre la propiedad, ${ }^{55}$ especialmente cuando trataran de vender la parte mancomunada que les correspondía. Además, posibilitaba que "personas extrañas" pudieran adquirir derechos de dominio sobre la propiedad. El término "persona extraña” era para referirse a un comprador sin vínculo sanguíneo con la familia o los condueños poseedores de un condueñazgo. ${ }^{56}$

Los condueñazgos comitecos tuvieron una base familiar, pero a finales del siglo xIX se modificó, al integrarse otros condueños externos al círculo familiar. El cambio se debió a la flexibilización de las compraventas entre condueños, los cuales buscaron "afianzar y asegurar las actividades económicas" ${ }^{57}$ y disminuir las contribuciones fiscales aumentando el número de condueños. No obstante, esta característica también dificulta el seguimiento

\footnotetext{
54 Aguilar Robledo, “Los condueñazgos”.

55 Los artículos 3714, 3715 y 3716 del Código Civil de 1884 establecían las obligaciones de los albaceas mancomunados.

56 AHC-CUID, No. 1582, exp. 42, f. 1.

57 FANDOs, "La formación histórica”, p. 65.
} 
de los condueños, pues la cantidad de propietarios con derechos sobre el condueñazgo no fue fijo, como lo evidencian las más de 34 solicitudes de venta. Aunque esas cifras sólo contemplan las notificaciones que llegaron al Juzgado de Primera Instancia de Comitán, esto es, las que tuvieron un proceso legal, sin descartar que hayan existido más acuerdos extrajudiciales.

De cualquier manera, es necesario distinguir el término mancomunidad realizando una crítica de fuentes, la cual permita observar lo que dice el documento y lo expresado entre líneas por los condueños, revisando las acciones cotidianas en el ejercicio de los derechos de propiedad. ${ }^{58}$ En Comitán el mercado de tierras que se observa a través de los condueñazgos es complejo, pues implica el traspaso de derechos por compraventa, que ocurre bajo una trama de negociaciones, esquemas de pago y acuerdos extrajudiciales para aprovechar los recursos naturales, los cuales fueron expresados en las notificaciones.

Por otra parte, los costos de venta de los derechos de propiedad en los condueñazgos de Comitán dependían de la extensión en hectáreas de la parte del condueñazgo ofrecido. Además, el vendedor y el comprador acordaban el esquema de pago, mismo que era enterado a todos los condueños en la notificación, por si decidían hacer uso del "derecho de tanto" y que tuvieran la oportunidad de presentar una oferta al vendedor, igualando o aumentando el precio.

Los montos de venta registrados variaban desde 165 hasta 6000 pesos dependiendo de la superficie, las condiciones del terreno y los recursos disponibles en la propiedad. En Comitán, durante el periodo de 1885 a 1914 el precio de la caballería de tierra, equivalente a 42.5 hectáreas, para los terrenos en condueñazgo, ${ }^{59}$ se mantuvo entre 100 y 200 pesos. Aunque la unidad de medida conocida como caballería de tierra ya había

58 Congost, Tierras, leyes, historia, p. 15.

59 Equivalencia referenciada en: AHC-CUID, No. 1465, exp. 83, f. 1. 
sido dejada atrás con la implementación del sistema métrico decimal en $1861,{ }^{60}$ en Comitán, y en Chiapas en general, se siguió utilizando para expresar la superficie de los terrenos.

Otro elemento que considero pertinente para el análisis de los condueñazgos tiene que ver con el tipo de moneda en que se hacía efectiva la transacción de venta. Una vez que el condueño contaba con el visto bueno para vender, el pago se hacía en efectivo en una sola exhibición, o bien, a plazos de dos o tres años. La moneda usada para pagar variaba entre el cuño de Guatemala y el de México, pero predominaron las transacciones hechas con moneda fraccionaria de Guatemala, seguido por la moneda de plata en pesos mexicanos, y en menor medida por moneda fraccionaria sudamericana. ${ }^{61} \mathrm{El}$ dominio de la moneda guatemalteca para cubrir los pagos obedece a diversos factores. Comitán se encontraba en el punto neurálgico de una de las vías de comunicación por donde transitaba el comercio de Guatemala hacia Chiapas y México. ${ }^{62}$ Por otro lado, era un centro agrícola y ganadero importante, que fue forjando capitales entre las familias comitecas dedicadas al comercio, el tráfico legal e ilegal de mercancías y a los servicios ligados con el comercio y abastecimiento de bienes y mercancías tanto manufacturadas como agrícolas. ${ }^{63}$

La concentración del capital debió buscar cauce entre las familias comitecas, comerciantes y otros actores sociales que llegaban a Comitán o tenían negocios vinculados con el comercio y la agricultura. De esta manera, parte del dinero era invertido en bienes, como los derechos de condueñazgo. A pesar de que el circulante fue uno de los problemas crónicos de la economía local desde la época colonial en Chiapas y Guatemala, los informes consulares mexicanos en 1896 hablaban de "la circulación

${ }^{60}$ Decreto de 15 de marzo de 1861 sobre el uso del sistema métrico decimal.

${ }^{61}$ AHC-CUID, No. 1613, exp. 90, f. 1.

62 Barrera, "Las Terrazas", p. 203.

${ }^{63}$ Barrera, "Las Terrazas"; Ruz, Savia india. 
excesiva de moneda guatemalteca" en Chiapas, ${ }^{64}$ a causa de que la moneda mexicana era empleada para los pagos fiscales y la guatemalteca era utilizada para el comercio de ganados, mercancías, productos agrícolas y otros bienes. ${ }^{65}$

Por otra parte, los condueñazgos comitecos se distinguieron por tener su origen en propiedades privadas, además del número moderado de condueños que componían cada propiedad. Estas condiciones también fueron observadas en otros lugares como San Luis Potosí, Veracruz, Hidalgo y en Jujuy al noroeste de Argentina. ${ }^{66}$ Sin embargo, las dinámicas de su administración y funcionamiento son una ventana a la forma de organización de las estructuras agrarias y los derechos de propiedad en Chiapas. La condición fronteriza de Comitán contribuyó a que los condueñazgos tuvieran varias singularidades en los mecanismos de compraventa y en el modo de apropiación de los recursos naturales.

\section{LA ADMINISTRACIÓN Y FUNCIONAMIENTO \\ DE LOS CONDUEÑAZGOS}

En este apartado resaltaré algunos rasgos de la administración interna y fiscal de los condueñazgos comitecos, así como el funcionamiento de estas propiedades en el mercado de tierras, utilizadas como garantías para el otorgamiento de hipotecas y créditos entre privados. No obstante, también quisiera señalar cómo los condueños organizaron el aprovechamiento de las aguas, bosques y pastizales mediante acuerdos verbales extrajudiciales y notariales.

64 Secretaría, Boletín Oficial, p. 273.

65 Secretaría, Boletín Oficial, pp. 270-273.

66 Escobar Ohmstede, "Los condueñazgos"; Escobar Ohmstede, "La estructura agraria”, Escobar OHMSTEde y Gordillo, “¿Defensa o despojo?”, FANDOS, "La formación histórica”. 
La contribución tributaria de los condueñazgos comitecos a finales del siglo xIx fue relevante para los ingresos de los municipios chiapanecos. En Chiapas, a partir de 1895 el cobro de las fincas rústicas mancomunadas fue una facultad de los ayuntamientos, con una tasa de $12 \%$ sobre la propiedad proindivisa o mancomunada. ${ }^{67}$ Esta medida tuvo dos objetivos: el primero, fortalecer los ingresos de los municipios e identificar catastralmente, a las propiedades que estuvieran proindivisas y mancomunadas. En segundo lugar, las autoridades estatales buscaron acelerar la división de los terrenos y avanzar en la individualización de la propiedad. Sin embargo, al realizar estas acciones no se consideraron las siguientes dificultades identificadas por Sánchez Rafael:

1) no reparó en el hecho de que los herederos podían ser menores de edad [en dado caso que había tutores] y que entonces no tendrían posibilidad de pagar la contribución, lo que podría incluso terminar en el embargo y remate de la propiedad, como en efecto ocurrió; 2) que sólo uno de los propietarios explotara la finca y fuera únicamente él quien pagara la tasa de 12 al millar; 3) que los condueños, para evadir al fisco, se constituyeran en una "sociedad legal", ya que este tipo de asociaciones estaban exentas del gravamen; 4) que en realidad no era el capital lo que se había gravado, sino su condición de indivisa o mancomunada, y en ese sentido su clasificación como un impuesto directo era cuestionable. ${ }^{68}$

Estas observaciones a la implementación del decreto estatal sobre fincas rústicas de 1895 que afectó a los condueñazgos impactaron en municipios donde predominaban esas formas de propiedad privada, como Comitán, Chiapa, San Bartolomé

67 Sánchez, "Reformas y finanzas”, p. 159.

${ }^{68}$ Sánchez, "Reformas y finanzas", p. 159. 
de los Llanos y San Cristóbal de Las Casas. ${ }^{69}$ Sin embargo, el impuesto de fincas rústicas también ayudó a identificar más condueñazgos que estaban proindivisos. Sobre todo, por los avisos de las autoridades municipales a los condueños que no estaban al corriente en el pago de ese impuesto. De esta manera, los funcionarios municipales (presidentes, síndicos y regidores) se encargaban de vigilar que "los vecinos [...] paguen las contribuciones de los terrenos que mancomunadamente poseen", ${ }^{70}$ como las notificaciones realizadas a "los propietarios del terreno mancomunado de San Juan Chamentic en el municipio de Las Margaritas", ${ }^{71}$ además del requerimiento hecho a uno de los dueños del terreno "proindiviso" llamado El Descuido en Socoltenango, para que se pusiera al día en sus pagos a la tesorería municipal. ${ }^{72}$

Estas acciones presionaron a los condueños que no utilizaban plenamente la propiedad o bien se encuadraban en los supuestos anteriormente expuestos para vender los derechos de propiedad sobre su condueñazgo y evitar el pago de contribuciones. Estos motivos explican el aumento en las compraventas de las propiedades mancomunadas en Comitán entre 1895 y 1928. De esta forma, se puede comprobar que, para los ingresos municipales, las contribuciones de los condueños por sus propiedades mancomunadas fueron importantes. ${ }^{73}$

En Comitán esta situación fue más notoria debido a la cantidad de propiedades proindivisas y mancomunadas privadas que había en el municipio. Por ejemplo, en la ranchería de Yocnajab, el comisario rural informó al jefe político que allí sólo había propiedades privadas y carecían de ejidos. ${ }^{74} \mathrm{El}$ aspecto fiscal

\footnotetext{
69 SÁnchez, "Reformas y finanzas”, p. 160.

70 SÁnchez, "Reformas y finanzas”, p. 160.

71 AHDSCLC, carp. 2755, exp. 267, f. 13.

72 AHDSCLC, carp. 2758, exp. 172, f. 1.

73 SÁnCHEZ, "Reformas y finanzas".

74 AHDSCLC, carp. 2755, exp. 273, f. 19.
} 
permite observar las presiones externas que recibieron las propiedades mancomunadas con el fin de dividirlas y convertirlas en propiedades individuales. También existen otras dinámicas indispensables de considerar para entender la función de los condueñazgos.

La administración y aprovechamiento de los recursos naturales, como los usos del agua y maderas en los condueñazgos, dependió de los acuerdos extrajudiciales y notariales realizados entre condueños. Sin embargo, en los condueñazgos comitecos el "desconocimiento" de los límites de la propiedad, alegado por los condueños para no cumplir con los acuerdos, provocó enfrentamientos legales. Sobre este aspecto, retomaré un caso acerca de la administración del agua concerniente a una controversia por una servidumbre de agua, ubicada en los terrenos de Chichimá en Comitán, la cual era propiedad de varios condueños. ${ }^{75}$

Los derechos de servidumbre de agua consistían en el acceso y uso que otros individuos podían hacer de las aguas existentes en otras propiedades, sin que necesariamente se hicieran acreedores a la titularidad de la posesión de las aguas; solamente podían servirse con fines útiles. ${ }^{76}$ En la parte del terreno de Chichimá correspondiente a Manuel Torres existían dos aguajes, ${ }^{77}$ y para aprovecharlos, Torres celebró un contrato de servidumbres de aguas notariado en marzo de 1903 con otros dos condueños: Abelino Aguilar y Abraham Aguilar, ${ }^{78}$ para que sus ganados pudieran hacer uso de los dos aguajes. Los problemas surgieron cuando Abelino Aguilar vendió su parte como condueño, incluida la servidumbre de agua, a Fidelino Guillén, Francisco Aguilar y Toribio Aguilar. Sin embargo, Tomás Torres

\footnotetext{
AHC-CUID, No. 1942, exp. 161.

76 Galván, Ordenanzas, p. 67; SuÁrez, "Industria y agua”, pp. 64-65.

77 Sitio donde pueden beber los ganados.

78 AHC-CUID, No. 1942, exp. 161, f. 11.
} 
desconoció el contrato e impidió a los nuevos condueños el uso de los aguajes construyendo una cerca. ${ }^{79}$

Los nuevos condueños de Chichimá impedidos de la servidumbre de agua lo denunciaron ante el Juzgado de Primera Instancia, donde dieron trámite al pleito. Sin embargo, los testimonios de los denunciantes y los testigos que fueron llamados al caso muestran las negociaciones y acuerdos previos celebrados entre los condueños para el manejo de los recursos naturales. Aunque algunos de esos acuerdos se formalizaron ante notario público, debió existir otro tipo de tratos verbales que no fueron registrados entre condueños, los cuales son más difíciles de rastrear a través de la documentación judicial.

$\mathrm{Al}$ respecto, los condueñazgos comitecos fueron muy dinámicos en el uso y tenencia de los recursos naturales. Los contratos legales y extrajudiciales se dejan ver en la documentación oficial por los pleitos sobre los recursos naturales. También ejemplifican los mecanismos cotidianos en la administración de estas formas de propiedad privada. Además, manifiestan la función de las autoridades locales e intermedias en estos procesos y abren otras interrogantes sobre la administración y usos del agua en Chiapas durante el siglo xix. Especialmente, si consideramos que los municipios fueron los encargados de otorgar permisos y concesiones de agua para usos domésticos y agrícolas. ${ }^{80}$

Los condueños también emplearon los contratos para acordar la utilización de las maderas y bosques existentes en los terrenos del condueñazgo. La regulación para el aprovechamiento de las maderas y bosques siguió el camino del agua mediante la celebración entre condueños de contratos notariales o bien por acuerdos verbales extrajudiciales. Los condueños se enfrentaban cuando decidían vender su parte correspondiente, incluyendo

\footnotetext{
79 AHC-CUID, No. 1942, exp. 161, f 1-1v.

80 AHC-CUID, No. 1732, exp. s/n, f.1.
} 
el uso y aprovechamiento de los recursos, como sucedió en el terreno de San Juan Chamentic en Las Margaritas.

En 1885 Oneciforo Aguilar demandó a Bacilio Villatoro por "la destrucción que le esta[ba] haciendo de las maderas del rancho Chamentic". ${ }^{81}$ El pleito por la utilización de las maderas radicó en que Villatoro había comprado la parte correspondiente del condueñazgo del terreno a Zacarías Aguilar, hermano de Oneciforo Aguilar. De esta forma, San Juan Chamentic había pertenecido a los dos hermanos como propiedad mancomunada, pero Bacilio Villatoro decidió hacer uso de las maderas en la propiedad cuando compró los derechos a Zacarías Aguilar. En respuesta, Oneciforo Aguilar exigió que se rescindiera el contrato entre su hermano y Villatoro, además de solicitar hacer uso del derecho de tanto que le correspondía como condueño. ${ }^{82}$

El aprovechamiento de los recursos naturales de los condueñazgos es un tema a investigar, pues existe una imbricación de derechos de propiedad legales y extrajudiciales que varían en cada condueñazgo. De esta forma, no es posible establecer reglas de operación específicas sobre la administración interna de los condueñazgos, y tampoco de las formas de aprovechamiento de los recursos naturales que en ellos existían, salvo de las disposiciones legales vigentes al respecto. Igualmente, para los condueñazgos en Comitán no logré identificar reglamentos internos entre los condueños, aunque no descarto que los hubiera de forma escrita o verbal, donde se detallaran los derechos, obligaciones y sanciones para cada condueño.

Los recursos legales interpuestos en las controversias entre condueños y permiten observar algunos aspectos sobre la administración de los recursos naturales. No obstante, destacan los acuerdos cotidianos verbales extrajudiciales, los cuales salían a la luz cada vez que los pleitos escalaban a otras instancias de

${ }^{81}$ AHC-CUID, No. 593, exp. s/n, f. 1.

82 AHC-CUID, No. 593, exp. s/n, f. 1. 
justicia local e intermedia. Gracias a estas ventanas de interpretación, fue posible rastrear las dinámicas en los derechos de propiedad sobre los recursos naturales en las propiedades privadas de Comitán.

\section{MECANISMOS DE COMPRA Y VENTA DE LOS DERECHOS \\ DE CONDUEÑAZGO}

Otra manera de observar y analizar los condueñazgos como propiedades privadas, consiste en estudiar los esquemas vinculados a las compraventas de derechos de propiedad. Anteriormente, enuncié la forma en que se establecían los montos de pago para la adquisición del derecho de propiedad, la cual se basaba en la extensión total de la parte correspondiente a vender del condueñazgo, el tipo de moneda utilizada y los plazos para pagar.

En los mecanismos de pago empleados para adquirir condueñazgos en Comitán, destacaron los financiamientos a plazos determinados entre el comprador y el vendedor. Por ejemplo, cuando una persona adquiría el derecho de condueñazgo sobre una propiedad, podía cubrir la totalidad del costo ante el vendedor, o bien recurrir a un esquema de pagos mediante un contrato de compraventa notariado. Cuando esto ocurría el comprador realizaba pagos parciales, algunos con intereses. En 1910, Porfirio Guillén convino la compra con Antonio Gallegos de los derechos de las fincas El Limón y anexos de San Ildefonso en Socoltenango. ${ }^{83}$ El precio de la transacción fue de 3000 pesos en moneda fraccionaria de Guatemala, que sería cubierto en dos años; primero, con un pago de 2000 pesos, más el interés de $5 \%$ anual, y al final, un pago de 1000 pesos. Una vez cubiertos los pagos, Guillén entregaría la escritura de la propiedad a Gallegos.

83 AHC-CUID, No. 1785, exp. 115, f. 1v. 
También, los condueñazgos sirvieron como garantías de hipotecas. Por ejemplo, en 1896 José Ángel Guillén compró el derecho de condueñazgo de San Vicente Enaltic en Comitán, con una extensión de 1931 hectáreas; el valor de la porción del condueñazgo era de 18620 pesos. ${ }^{84}$ Esta transacción fue una de las más altas que logré identificar en Comitán. Los dueños anteriores, Eusebio y Justina Gordillo, estaban al corriente de sus pagos del impuesto de fincas rústicas pero tenían una hipoteca sobre la propiedad a favor de Leopoldo de la Vega por 5000 pesos en pesetas de plata de Guatemala y con un interés de $1 \%$ mensual. ${ }^{85} \mathrm{Al}$ parecer, también la hipoteca pasó al nuevo condueño, que siguió realizando los pagos. Estas condiciones permiten observar desde otra cara el manejo de los derechos de propiedad y los instrumentos financieros que estuvieron involucrados en la posesión de la tierra en condueñazgo.

Algunas ventas, además de la tierra, también incluían a "la población y la deuda de los sirvientes". ${ }^{86}$ Aunque estas propiedades privadas en condueñazgo las hacían pasar como fincas en los contratos notariales, los precios de venta fueron muy elevados comparados con los montos de venta de algunas partes de condueñazgos que no excedían los 1000 pesos en moneda mexicana o guatemalteca. Por ejemplo, la finca San Francisco Cotana, propiedad de Lisandro Castellanos, fue vendida a Conrado de Jesús Domínguez por 15000 pesos en $1889 .{ }^{87}$

Los últimos casos muestran operaciones de compraventa que fueron reguladas y asentadas mediante protocolos notariales en Comitán y San Cristóbal de Las Casas por los notarios Herminio Cancino, Juan José de León y Flavio A. Paniagua, siendo los dos primeros los más activos en los procesos de compraventa de condueñazgos en Comitán. También, en sus notarías

${ }^{84}$ AHC-CUID, $N$, No. 28, exp. 21, f. 2.

${ }^{85}$ AHC-CUID, $N$, No. 28, exp. 21, f. 1-2.

86 AHC-CUID, N. No. 590, exp. s/n, f. 11v.

87 AHC-CUID, N. No. 590, exp. s/n, f. 11v. 
se registraron los contratos que amparaban la formación de sociedades agrícolas en el departamento de Comitán entre 1900 y la década de 1930.

Sobre las formas de compraventa de partes de condueñazgos en Comitán, destaco la utilización de sistemas de crédito e hipotecarios para concretar los pagos, además del dinamismo del mercado de tierras en Chiapas y el movimiento de los capitales de empresarios, comerciantes y políticos que estaban involucrados en otros negocios y que encontraban en la tierra un medio de inversión y flujo para sus capitales.

\section{LAS SOCIEDADES AGRÍCOLAS ¿SUCESORAS DE LOS CONDUEÑAZGOS?}

Las dinámicas de la propiedad privada en Chiapas vistas a través de los condueñazgos permiten plantear otras cuestiones sobre sus orígenes, desarrollo y desaparición. Un primer punto que puedo observar sobre la formación de los condueñazgos y su permanencia durante el siglo XIX se encuentra en las leyes desamortizadoras de Chiapas aplicadas en diferentes momentos entre 1826 y después de 1856, este último periodo en correspondencia con las leyes federales mexicanas de desamortización de bienes. También considero que se debe seguir la pista a las tierras comunales indígenas, especialmente a las propiedades comunales desamortizadas desde mediados del siglo XIX.

Aunque en este trabajo no fueron discutidas, existen otros análisis que lo han realizado con diferentes escalas de profundidad. Por ejemplo, Mario Humberto Ruz, Gloria Pedrero y Óscar Barrera muestran indicios de la relación existente entre la desamortización de tierras comunales y la conformación de condueñazgos. ${ }^{88}$ No obstante, estas dinámicas en la propiedad privada no fueron exclusivas de Chiapas, como fue demostrado

88 Barrera, Las Terrazas; Pedrero, “La nueva estructura”; Ruz, Savia india. 
en las investigaciones sobre los condueñazgos en San Luis Potosí, Veracruz e Hidalgo, donde también se puede ubicar el destino de las tierras comunales que terminaron conformando condueñazgos. ${ }^{89}$

Asimismo hay que considerar que la mayoría de los condueñazgos tuvieron su base en la propiedad privada, incluso en momentos tan tempranos como los siglos XVII y XVIII. ${ }^{90}$ Los vínculos familiares y la transmisión por medio de herencia de grandes propiedades a los hijos contribuyeron a que los terrenos tuvieran muchos dueños, pero manteniendo la proindivisión y el dominio directo de la propiedad. A éstos se fueron agregando otros actores que adquirieron la condición de condueños durante la coyuntura de las leyes desamortizadoras y el impulso privatizador de la tierra de mediados del siglo XIX.

Los condueñazgos se consolidaron como una propiedad privada en Comitán, sin llegar a ser una categoría de propiedad agraria estática. Antes bien, las dinámicas en el aprovechamiento de los recursos de estas propiedades y la relación entre los condueños se modificaban constantemente siguiendo diversos intereses económicos, políticos y sociales, los cuales sancionaban las prácticas cotidianas legales y extrajudiciales observadas en cada condueñazgo, como el uso de las aguas, bosques y pastizales, además de la compraventa de los derechos de dominio e hipotecas sobre una parte del condueñazgo. ${ }^{91}$ Este entramado de derechos de propiedad se apuntalaría con los nuevos marcos legales y positivos, como la expedición del código civil de $1884 .^{92}$

De esta forma, los condueñazgos comitecos perduraron hasta la década de 1930. Después de ese momento, ya no pude

89 Escobar Ohmstede, “Los condueñazgos"; Escobar Ohmstede, "La estructura agraria”; Escobar OHMSTEde y Gordillo, “¿Defensa o despojo?”; RANGEL, "Los comuneros".

90 Ruz, Savia india.

91 Aguilar, “Los condueñazgos”, p. 157.

92 FALcón, “Desamortización”, p. 71. 
rastrearlos mediante la documentación oficial y judicial; muy probablemente hayan desaparecido mediante el fraccionamiento de la propiedad entre los condueños a causa de la nueva normatividad agraria o bien por la división y repartición de las propiedades proindivisas mediante hijuelas entre los miembros de una familia.

Sin embargo, queda un punto pendiente de los condueñazgos y su relación con las sociedades agrícolas, misma que apareció en los documentos consultados. Al respecto, Miguel Aguilar Robledo propuso que los condueñazgos fueron "una forma transitoria de propiedad privada proindivisa, producto tanto de la desintegración de las haciendas como de la conformación de las sociedades agrarias" ${ }^{93}$ Pero para el caso de Comitán, la hipótesis de Aguilar Robledo no se ajusta, pues los condueñazgos y las sociedades agrícolas no estaban vinculadas; tampoco se observa que los condueñazgos hayan transitado hacia esa forma de propiedad.

Las sociedades agrícolas que logré identificar en Comitán se conformaron a principios del siglo xx. La constitución de las sociedades agrícolas, a diferencia de los condueñazgos, estaba protocolizada ante notario público y tenía plazos en su vigencia; por lo general cada diez años se renovaba el contrato que mantenía unidos a los socios, que indistintamente podían ser de un mismo lugar, ser familiares o simplemente asociarse por conveniencia de intereses. Esta característica también fue localizada en las pesquisas sobre condueñazgos en las Huastecas en México y el noroeste Argentino, ${ }^{94}$ a diferencia de las localizadas en el oriente de Yucatán, donde los socios sí provenían de una misma comunidad. ${ }^{95}$

\footnotetext{
93 Aguilar, "Los condueñazgos”, p. 153.

94 Escobar Ohmstede y Gordillo, “¿Defensa o despojo?”, p. 35; Fandos, "La formación histórica”, p. 56.

95 HoIL, “La configuración agraria”, p. 167.
} 
Además, destaca el funcionamiento de las sociedades agrícolas, con una junta directiva y un administrador electos entre los socios. Los miembros de la junta directiva y el administrador se encargaban de recolectar y pagar las contribuciones fiscales de los socios ante el municipio y el gobierno del estado. Otra de las distinciones radicaba en el número de socios, pues como se vio con anterioridad, mientras los condueñazgos apenas llegaron a una decena de condueños, las sociedades agrícolas, como la de Santo Domingo Lopoj, tenía 395 socios en 1934. ${ }^{96}$

No descarto que antiguos condueños se hayan integrado como socios en alguna sociedad agraria, pero hasta este momento no puedo establecer un vínculo fuerte que indique que los condueñazgos continuaron como propiedad proindivisa en la forma de sociedades agrícolas. Al menos para el caso de Comitán, considero que estamos ante dos formas de propiedad privada totalmente distintas. Hay, por tanto, la necesidad de diferenciar estas propiedades, lo cual podría ser un avance en el conocimiento de las variables regionales de los condueñazgos y las sociedades agrícolas en México y Latinoamérica para los siglos XIX y XX.

Los condueñazgos en Comitán como forma de propiedad privada comienzan su declive con las políticas desamortizadoras de finales del siglo xIx, por el impulso a la privatización de la tierra delimitando propiedades, creando catastros fiscales y elaborando una cartografía de la propiedad. ${ }^{97}$ Este conjunto de políticas estuvieron encaminadas a buscar el dominio pleno de la tierra. ${ }^{98}$ Sin embargo, sería hasta el siglo xx que estas formas de propiedad desaparecieron como tales, ante la llegada de otros procesos políticos y agrarios, los cuales merecen una

\footnotetext{
${ }^{96}$ AHC-CUID, No. 2954, exp. 86, f. 1.

97 Falcón, "Desamortización”, p. 60.

98 Escobar Ohmstede, “Lo agrario en Oaxaca”, p. 79.
} 
revisión aparte debido a la complejidad de las coyunturas políticas y las transformaciones de los derechos de propiedad.

\section{CONSIDERACIONES FINALES}

El análisis de los condueñazgos comitecos y su vínculo con el proceso de desamortización de la tierra nos deja varias líneas de análisis que pueden ser futuros puntos de partida y referencia para los estudios agrarios en Chiapas y México. En primer lugar, quisiera destacar el proceso de formación y continuidad de las propiedades privadas en Comitán desde finales del siglo xviII y que se mantuvo durante la siguiente centuria.

El segundo aspecto lo rescato de un par de interrogantes sobre el destino de las tierras comunales en Chiapas: ¿en dónde podemos localizar estas propiedades después de las leyes desamortizadoras?, y ¿cuáles fueron las dinámicas en las comunidades indígenas y ladinas para conservar o perpetuar este tipo de propiedad? Resultaría interesante abundar en esta perspectiva, pues arrojaría luces sobre otros procesos relacionados con la tierra, como los tipos de dominio de las propiedades.

Finalmente, un tercer aspecto lo encuentro en la continuidad de este tipo de propiedades durante las primeras cuatro décadas del siglo xx, cuando confluye con otros procesos, como la revolución mexicana, las reivindicaciones agraristas por la tierra y la movilización de trabajadores agrícolas migrantes entre la frontera de Chiapas y Guatemala. En Chiapas estas coyunturas tienen una temporalidad distinta e implicaciones importantes respecto a las observadas en el centro o en el norte de México. La pervivencia de los condueñazgos y la conformación de sociedades agrícolas durante el siglo xx es un buen punto de partida para otros análisis, considerando la complejidad de las estructuras y las problemáticas agrarias que resultaron de los procesos históricos anteriormente reseñados. Además, queda pendiente conocer a fondo otras variantes regionales de los condueñazgos 
en Chiapas, a fin de destacar las características generales de estas formas de propiedad y la influencia que tuvieron las políticas desamortizadoras de mediados del siglo xIx.

\section{SIGLAS Y REFERENCIAS}

AHC-CUID, $N$ Archivo Histórico de Comitán, Centro Universitario de Información y Documentación, sección Notarias, Universidad de Ciencias y Artes de Chiapas, Tuxtla Gutiérrez, Chiapas, México.

AHDSCLC Archivo Histórico de la Diócesis de San Cristóbal de Las Casas, San Cristóbal de Las Casas, Chiapas, México.

AHJLA Archivo Histórico Judicial de Los Altos, San Cristóbal de Las Casas, Chiapas, México.

Aguilar Robledo, Miguel, "Los condueñazgos del oriente de San Luis Potosí, México, de finales del siglo xix a principios del siglo xx: algunas reflexiones teóricas”, en Vetas, 2 (2000), pp. 151-189.

Barrera Aguilera, Óscar Javier, “Las Terrazas de Los Altos. Lengua, tierra y población en la Depresión Central de Chiapas", tesis de doctorado en historia, México, El Colegio de México, 2017.

Barrera Aguilera, Óscar Javier, Las terrazas de Los Altos: lengua, tierra y población en la Depresión Central de Chiapas, 1775-1930, San Cristóbal de Las Casas, Chiapas, Centro de Investigaciones Multidisciplinarias sobre Chiapas y la Frontera Sur, Universidad Nacional Autónoma de México, Consejo Estatal para las Culturas y las Artes, 2019.

Código Civil del Distrito Federal y territorios de Tepic y Baja California: promulgado en 31 de marzo de 1884, México, Librería de la Viuda de Ch. Bouret, 1902.

Congost, Rosa, Tierras, leyes, historia. Estudios sobre "la gran obra de la propiedad", Barcelona, Crítica, 2007.

Congreso del Estado Libre y Soberano de Chiapas, Colección de las leyes agrarias y demás disposiciones que se han emitido en relación al ramo de tierras, San Cristóbal de Las Casas, 1878. 
Congreso del Estado Libre y Soberano de Chiapas, Ley y reglamento para la división y reparto de ejidos en el estado de Chiapas, Tuxtla Gutiérrez, Imprenta del Gobierno, 1893.

De Vos, Jan, Vivir en frontera. La experiencia de los indios de Chiapas, México, Instituto Nacional Indigenista, Centro de Investigaciones y Estudios Superiores en Antropología Social, 1997.

Escobar Ohmstede, Antonio, "La estructura agraria en las Huastecas, 18801915”, en Escobar Ohmstede y Rojas Rabiela (coords.), 2001, pp. 179-196.

Escobar Ohmstede, Antonio, "Lo agrario en Oaxaca a la luz de la desamortización de la segunda mitad del siglo xix. Un acercamiento desde los Valles Centrales", en Escobar Ohmstede, Medina Bustos y Trejo Contreras (coords.), 2015, pp. 71-133.

Escobar Ohmstede, Antonio, "Los condueñazgos indígenas en las Huastecas hidalguense y veracruzana: ¿defensa del espacio comunal?”, en Escobar OHMSTEDe (coord.), 1993, pp. 171-188.

Escobar Ohmstede, Antonio y F. Schryer, "Las sociedades agrarias en el norte de Hidalgo, 1856-1900", en Mexican Studies/Estudios Mexicanos, 8: 1 (1992), pp. 1-21.

Escobar Ohmstede, Antonio y Jaqueline Gordillo, “¿Defensa o despojo? Territorialidad indígena en las Huastecas, 1856-1930”, en Escobar OHMSTEde, Gudiño, Hernández, Gutiérrez, Embriz y Acosta, 1998, pp. 17-74.

Escobar Ohmstede, Antonio y Teresa Rojas Rabiela (coords.), Estructuras y formas agrarias en México. Del pasado y del presente, México, Registro Agrario Nacional, Archivo General Agrario, Centro de Investigaciones y Estudios Superiores en Antropología Social, 2001.

Escobar Ohmstede, Antonio (coord.), Indio. Nación y Comunidad en el México del siglo XIX, México, Centro de Investigaciones y Estudios Superiores en Antropología Social, Centro de Estudios Mexicanos y Centroamericanos, 1993.

Escobar Ohmstede, Antonio, José Marcos Medina Bustos y Zulema Trejo Contreras (coords.), Los efectos del liberalismo en México, siglo XIX, México, El Colegio de Sonora, Centro de Investigaciones y Estudios Superiores en Antropología Social, 2015. 
Escobar Ohmstede, Antonio, Ma. Rosa Gudiño, Elia Rocío HernánDez, Ana Ma. Gutiérrez, Arnulfo Embriz y Gabriela Acosta, Estudios campesinos en el Archivo General Agrario, México, Registro Agrario Nacional, Centro de Investigaciones y Estudios Superiores en Antropología Social, 1998, vol. 1 .

Escobar Ohmstede, Antonio, Romana Falcón y Martín Sánchez RodríGUEZ (coords.), La desamortización civil desde perspectivas plurales, México, El Colegio de México, Centro de Investigaciones y Estudios Superiores en Antropología Social, El Colegio de Michoacán, 2017.

EsCRICHe, Joaquín, Diccionario razonado de legislación y jurisprudencia, Madrid, Librería de la Señora Viuda e hijos de Don Antonio Calleja Editores, 1847, t. I.

Falcón, Romana, "Desamortización a ras del suelo, ¿el lado oculto del despojo? México en la segunda mitad del siglo XIX", en Ponce Alcocer y Pérez Rosales (coords.), 2009, pp. 59-86.

FANDos, Cecilia, "La formación histórica de condueñazgos y copropiedades en las regiones de las Huastecas (México) y las tierras altas de Jujuy (Argentina)", en Revista de Historia Iberoamericana, 10: 2 (2017), pp. 49-79.

Galván Rivera, Mariano, Ordenanzas de tierras y aguas, o sea formulario geométrico judicial para la designación, establecimiento, mensura, amojonamiento y deslinde de las poblaciones y todas suertes de tierras, sitios, caballerias $y$ criaderos de ganados mayores y menores, y mercedes de agua, París, Rosa y Bouret, 1856.

García de León, Antonio, Resistencia y utopía. Memorial de agravios y crónica de revueltas y profecías acaecidas en la provincia de Chiapas durante los últimos quinientos años de su historia, México, Ediciones Era, 1985.

Hoil Gutiérrez, Julio César, "La configuración agraria del oriente de Yucatán. Insurrección maya, tierras y reforma agraria, 1847-1935", tesis de doctorado en historia, México, Centro de Investigaciones y Estudios Superiores en Antropología Social, 2016.

KOuRí, Emilio, "Sobre la propiedad comunal de los pueblos, de la Reforma a la Revolución”, en Historia Mexicana, LXvi: 4 (264) (abr.-jun. 2017), pp. 1923-1960.

Márquez, Esaú, Rafael Araujo y Rocío Ortiz Herrera (coords.), Estadonación en México. Independencia y Revolución, México, Universidad de Ciencias y Artes de Chiapas, 2011. 
Méndez ZÁrate, Armando, "Estructuras agrarias, territorio y trabajo: La 'Bocacosta' centroamericana (Soconusco, Guatemala y El Salvador, 18211890)", tesis de doctorado en historia, México, Centro de Investigaciones y Estudios Superiores en Antropología Social, 2018.

Obara-Saeki, Tadashi y Juan Pedro Viqueira Alban, El arte de contar tributarios. Provincia de Chiapas, 1560-1821, México, El Colegio de México, 2017.

Olivera Bustamante, Mercedes y María Dolores Palomo Infante (coords.), Chiapas: de la Independencia a la Revolución, México, Centro de Investigaciones y Estudios Superiores en Antropología Social, Consejo de Ciencia y Tecnología del Estado de Chiapas, 2009.

Ortiz Herrera, María del Rocío, "Lengua e historia entre los zoques de Chiapas. Castellanización, desplazamiento y permanencia de la lengua zoque en la Vertiente del Mezcalapa y el Corazón Zoque de Chiapas (1870-1940)", tesis de doctorado en ciencias sociales, Zamora, Michoacán, El Colegio de Michoacán, 2006.

Ortiz Herrera, María del Rocío (coord.), Ayuntamientos chiapanecos: fiscalidad, elecciones, cindadanía y defensa de bienes de comunidad desde la Colonia hasta el inicio de la Revolución en Chiapas, México, Universidad de Ciencias y Artes de Chiapas, El Colegio de Michoacán, 2018.

Ortiz Herrera, María del Rocío, “Abogados y apoderados en pleitos de tierras, Chiapas, 1833-1872”, en Caravelle, 112 (2019), pp. 41-56.

Ortiz Herrera, Rocío, Benjamín Lorenzana Cruz y Miguel Ángel ZebaDÚA CARBONELL (coords.), Chiapas durante los años del ange agroexportador, 1870-1929, México, Universidad de Ciencias y Artes de Chiapas, 2018.

Palomo Infante, María Dolores, "Las tierras en disputa: reflexiones sobre la Ley de desamortización en Chiapas a través del análisis de los pleitos, 18561900”, en Escobar Ohmstede, Falcón y Sánchez Rodríguez (coords.), 2017, pp. 483-518.

Pedrero Nieto, Gloria, "La nueva estructura agraria de Chiapas, 18531910", tesis de doctorado en historia, México, Universidad Autónoma Metropolitana, 2009.

Pedrero Nieto, Gloria, "La evolución del ejido en Chiapas (siglo xix)”, en Olivera Bustamante y Palomo Infante (coords.), 2009, pp. 339-366. 
Pedrero Nieto, Gloria, "Las divisiones políticas en Chiapas: siglos xvi y xix”, en Márquez, Araujo y Ortiz Herrera (coords.), 2011, pp. 211-261.

Pérez Castañeda, Juan Carlos, "Los condueñazgos en México durante el siglo xIx”, en Signos Históricos, xx: 40 (2018), pp. 178-231.

Ponce Alcocer, María Eugenia, y Laura Pérez Rosales (coords.), El oficio de una vida. Raymond Buve, un historiador mexicanista, México, Universidad Iberoamericana, 2009.

RANGel Silva, José Alfredo "Los comuneros, el abogado y el senador. Cultura política y orden liberal a fines del porfiriato", en Historia Mexicana, LXIv: 3 (255) (ene.-mar. 2015), pp. 937-1000.

Reyes Ramos, María Eugenia, El reparto de tierras y la política agraria en Chiapas 1914-1988, México, Universidad Nacional Autónoma de México, 1992.

Ruz, Mario Humberto, Savia india, floración ladina. Apuntes para una historia de las fincas comitecas (siglos XVIII y XIX), México, Consejo Nacional para la Cultura y las Artes, 1992.

Sánchez Rafael, Miguel Ángel, “Reformas y finanzas en la esfera municipal. Chiapas. 1881-1915”, en OrTiz Herrera (coord.), 2018, pp. 141-183.

Sánchez Rafael, Miguel Ángel y Rocío Ortiz Herrera, "Fincas rústicas y finanzas en Chiapas, 1881-1915", en Ortiz Herrera, Lorenzana Cruz y Zebadúa Carbonell (coords.), 2018, pp. 129-171.

Secretaría de Relaciones Exteriores, Boletín Oficial de la Secretaría de Relaciones Exteriores, México, Imprenta del Gobierno, 1895.

SuÁrez Cortez, Blanca Estela, "Industria y agua en el centro de México (1835-1850)”, en Suárez Cortez y Birrichaga Gardida, 1997, pp. 13-92.

SuÁrez Cortez, Blanca Estela y Diana Birrichaga Gardida, Dos estudios sobre usos del agua en México (siglos XIX y XX), México, Instituto Mexicano de Tecnología del Agua, Centro de Investigaciones y Estudios Superiores en Antropología Social, 1997.

Torres Freyermuth, Amanda Úrsula, "La legislación agraria chiapaneca y la respuesta de los pueblos al proceso de desamortización, siglo XIX", en Escobar Ohmstede, Falcón y SÁnchez Rodríguez (coords.), 2017, pp. 449-480. 
Venegas González, Alicia, "El proceso de reparto de tierras comunales en Michoacán y su documentación (1827-1915)”, en Legajos. Boletín del Archivo General de la Nación, 16 (mayo-ago. 2018), pp. 101-123.

Viqueira Alban, Juan Pedro, "Chiapas y sus regiones", en Viqueira Alban y Ruz (eds.), 2004, pp. 20-40.

Viqueira Alban, Juan Pedro y Mario Humberto Ruz (eds.), Chiapas: los rumbos de otra historia, México, Universidad Nacional Autónoma de México, Centro de Investigaciones y Estudios Superiores en Antropología Social, 2004. 